\title{
Anatomical Basis of Memory and Neural Sciences
}

\author{
Prof. (Dr) Archana Lala \\ (Director, S.R.Group of Institutions, Jhansi, India)
}

\begin{abstract}
This paper introduces a novel method for human memory or learning process that employs a set of association, impression \& repetition. The output of the biological neurons are used together to make a decision. Experimental results for human memory and laws of learning confirm that the proposed method lends itself to higher classification accuracy relative to existing technique.
\end{abstract}

Keyword: Anatomical basis of Memory, Biological Neurons, Neural Network, Neural Science, Simulation.

\section{Introduction}

"The man whose acquisitions stick is the man who is always achieving and advancing whilst his neighbours, spending most of their time relearning what they once knew, but have forgotten simply hold their own.” Professor William Jones.

According to the noted psychologist, Professor Carl Seashore, an average man does not use above ten percent of his actual inherited capacity for memory. He wastes the ninety percent by violating the natural laws of remembering.

These natural laws of remembering are only three:-

1.1 Association

1.2 Impression

1.3 Repetition

Any one who practices these can move about with an air of confidence. Mark the word "AIR"n because it makes one to remember the three laws, i.e. A for association. I for Impression and R for Repetition.

\section{Law Of Association}

The word air explains the first law of Association. According to Professor James "Our mind is essentially an associating machine." So an educated memory depends upon an organized system of association.

Since birth, associations are formed in a child with his mother. Whenever he is hungry or in trouble he cries and his mother runs to him. The mother becomes a familiar form to him. Later when he has learnt the word "Mummy" as a form of address for his mother, this word automatically comes out of his mouth when ever he is in trouble. In the same way a person whenever he is in trouble may take the name of God. The word "God" will come out from his mouth whenever he is in trouble or despair. This automatic reproduction of the word "Mummy" or "God" is due to two factors which govern the laws of association:-

2.1 Persistence of the associations and

2.2 Their number

Therefore the memory will depend upon the number of associations and their repetitions. The more diverse and multiple are the associations, the better is the memory. Forming of various associations in the brain is thinking which is a very important factor in memory. The subject is assimilated by this process. New thoughts come. How? An electronic machine is fed with a number of problems. A button is pressed. A chain of reactions takes place within it and a solution comes out. This machine can even play a game of chess. Thinking is forming a number of associations in various ways. The more the thinking, the more the associations. The centers start working in cooperation with one another and new thoughts appear automatically. It is just like mixing a number of chemicals and the formation of a new compound not yet known. New thoughts (new compounds) may be a systematic process like research or may be like chance discoveries.

The human brain has a number of association fibres. The fibres connect the numerous centers in various ways. The centres of sight, hearing. Smell, taste and touch are in communication with one another through these association fibres. In the brain the medial longitudinal bundle which connects the cranial nuclei of the brain stem, is the first to show myelination (Sixth month) and is soon followed by vestibulo-spinal, reticulospinal and tecto-spinal tracts. The cerebellar connections are myelinated in the eighth month. The cortico-pontocerebellar connections and the pyramidal tracts become myelinated at about the same time. The projection fibres 
become myelinated before correlation areas of the cerebral cortex. Certain association fibres do not get myelinated till the age of 17. All fibres get myelinated before 25. There is much evidence (Langworthy, 1927 and 1929) that tracts become myelinated at about the time they become functional. (windle 1940).

It has been seen that some people become brilliant when they attain a certain age between 17 years and 25 years. The appearances of the last molar teeth vary between the ages of 17 and 25 . They are known as "Wisdom teeth." People might have noticed some relation between the appearance of these teeth and intelligence. Some are intelligent even before 17 and some never become intelligent. The explanation for this is that a person has started using his association fibres at an early age but full maturity is attained between 17 and 25 , the person who has never used his fibres, remains dull even after 25 years. He is like one who has never played a game. All games require practice i.e. persistence of associations and the number of their repetitions. Mathematics started as a game. Now it has attained the status of science. But its learning is governed by the same law of associations as in games.

A fact to be remembered should be associated with a many senses as possible. It is said that the human brain can absorb 200,000 distinct facts. But if these facts are associated with one another, the capacity of the brain to absorb more will be limitless.

Students find anatomy a difficult subject to remember. No doubt, the facts concerning individual structures are innumerable. If they are learnt as isolated facts, the goal will never be achieved and the brain's capacity will be exhausted and no room will be left to absorb anything else.

"Of the two men with the same outward experiences, the one who thinks over his experiences most, and weaves then into the most systematic relations with each other will be the one with the best memory."

How to link facts together? The answer is:-

2.1.1 Find their meaning

2.1.2 Think them over by answering the six friends which are:-

Why and How?

When and Where?

Who and What?

2.1.3 Make a word or a sentence which may be absurd or nonsense or even vulgar.

2.1.4 Arrange in alphabetical order if it helps.

2.1.5 Arrange the facts in twos or threes.

2.1.6 Associate the facts with what is already known or with some familiar or interesting things, ideas or visions.

2.1.7 Associate by similarity or contrast.

2.1.8 Associate with rhymes.

2.1.9 Associate with as many senses as possible.

2.1.10 Use any other method which suits you.

If a student dissects the whole body himself, cleanses the structures thoroughly, reads the book and compares the description given in the book with that which he is actually seeing, observes the structures from all angles and practices visualization and memory drawing of the structures seen, and continues practicing diagrams till the desired accuracy is attained, he will have a good memory for Anatomy. If he attends demonstrations and lectures, he will get additional ideas about the human body. Thus he will be using maximum number of his senses i.e. his eyes, his ears, his touch, and his brain.

Dissection (actual specimens) and diagrams are the two most important methods of learning Anatomy. Diagrams improve observations. A person can not draw if his mental picture is hazy. Diagrams will tell him that he has missed many important facts which he ought to have observed. So they are the aids for efficient observation and accurate mental picture. The relation of a structure is nothing but its association with other structures. While dissecting one must observe the structure in relation to the other, i.e., immediate neighbours and distant important neighbours. Anyone neglecting the above methods is putting unnecessary burden on his memory. The body is a three dimensional figure. So book diagrams can not replace the actual specimens. For accurate three dimensional visualization, actual specimens are essential. The students neglect the right method and call anatomy a difficult subject. It really becomes difficult when dissection is neglected. A student must take interest in dissection because things associated with pleasure are retained linger than those associated with pain.

\section{Law Of Impression}

Is to get a clear picture of the thing one wants to attain. It requires concentration. By constant practice and patience one can acquire this quality. Eugene Grace, the millionaire and the president of the Bethlehem Steel Company says, "If there is anything that I have leaned which is more important than anything else and which I practice everyday under any all circumstances, it is concentration on the particular job I have in hand." 
Concentration creates interest. Interest brings in more concentration. One must start work in the right sprit following the right methods. This work will create interest in the job.

Interest will create more concentration. More concentration means more interest and more work. Thus a virtuous circle is formed and elevates the person to supreme joy or bliss. If a person does not work, he loses interest and loss of interest brings about loss of concentration and this result in less work. A vicious circle is formed and the person becomes depressed and dejected.

Impression can be visual, auditory, olfactory, gustatory or tactile. The visual impressions are the most important. There is a Chinese proverb, "One time seeing is worth a thousand times hearing." Most of the people are eye minded. They can remember better anything which they have seen. Some are ear minded. They can remember better anything which they have heard. Whether a man is eye minded or ear minded, he can always try to get a deep impression of what he wants remember. Thomas Edison says, "The average person's brain does not observe a thousandth part of what the eye observes. It is almost incredible how poor our powers of observation-genuine observation-are."

Observation requires practice. One must pay sufficient attention with interest and observe accurately. One may be poor in observation and think himself to be of poor memory. Actually his observation is poor. Lincoln read aloud everything he wished to remember giving his explanation. "When I read aloud, two senses catch the idea: first, I see what I read; second, I hear it, and therefore I can remember it better." His memory was extraordinary.

The ideal thing is not only to see and hear but also to touch, to smell and to taste the thing to be remembered. Eye impression stick better than the ear impressions. There is anatomical basis for this. All sensory nerves are nerves of knowledge. The optic nerve is twenty times thicker than the auditory nerve. The optic nerve contains $800,000-1,000,000$ fibres. The cochlear nerve contains 27,000 fibres. The lateral geniculate body concerned with vision is larger than the medial geniculate body which is concerned with vision is larger than the medial geniculate body which is concerned with hearing. The superior corpora quadrigemina concerned with vision are larger than the inferior corpora quadrimina concerned with hearing. The cortical representation of vision is larger than the cortical representation of hearing. The number of association fibres from the vision centres is more than those from the hearing centres.

In practical experience also we often remember a man's face though we can not recall his name. Good memory is due to good observation. The first year student has poor observation. By the time be become a doctor, he develops good observation. This can be represented diagrammatically as follow:-

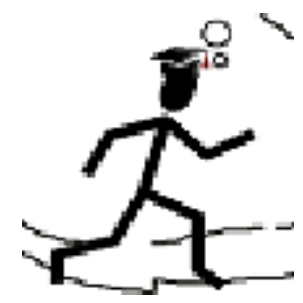

Fig. 1

ENTERENCE (First year)

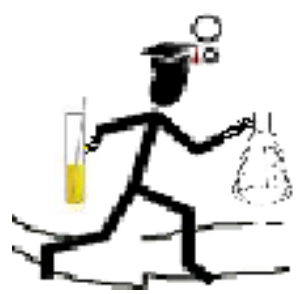

Fig. 2

EXIT (Fourth year)

Note the following difference:-
1. Poor Observer
2. Bad listener
3. Talkative
4. Poor thinker
5. Shirker
6. Hates to handle even the cadaver

7. In a great hurry to run away from practicals

The qualities of the person are represented diagrammatically by the difference in size of the regions concerned. Small region means disuse atrophy and large regions mean overwork hypertrophy.

\section{Law Of Repetition}

Pandit recite Vedas and Muslims recite Koran from memory. How do they do it? They have committed the holy books to memory by the law of repetition. Things can be learnt by blind mechanical going over a thing by rote. But this has limited value. Intelligent repetition has a wider scope. "A man who repeats a thing over and over until he commits it to memory, is using twice as much time and energy as is necessary to achieve the same results when the repeating process is done at judicious intervals." This is an important discovery about memory. 
This is two factors:-

4.1 During the intervals between repetitions, the subconscious mind is busy in making associations. According to Ranson \& Clark, "A brief sensory experience sending impulses into the cortex nay be followed by prolonged activity there in addition to the external response. Perhaps even memory may be explainable in this "storage" of impulses in reverberating circuits."

4.2 The mind gets rest in the interval and is refreshed. A fatigued mind is not receptive to anything. A fatigued nerve can not be stimulated. Memory has a physical basis. This basis is the brain. The brain is injured in certain head injuries resulting in the loss of memory (Amnesia). It may be for limited periods or permanent. Generalized loss of memory is found in secondary dementia.

Sir Richard Burton, the translator of the "Arabian Nights", spoke 27 languages like a native. He says " I have never studied or practiced any language for more than fifteen minutes at a time, after the brain lost its freshness."

Psychological experiments have shown that of the new material we have learned, we forget more during the first eight hours than during the next thirty days. So before going to examinations, one must go through one's notes and refresh one's memory.

The three fundamental elements of memory are the three qualities of memory.

i. Reception (Registration)

ii. Retention

iii. Reproduction (Recall)

In order to remember these three $\mathrm{R}$, of the fundamental elements, associate them with sex (or conception) i.e. the seed is received and reproduced.

Good reception means quick learning. It depends mainly on concentration and interest. Defects of registration are usually due to disordered attention.

Good retention means that whatever has been learnt can be retained in the brain for a long time. It depends mainly on repetition (revision). Failure of retention may be due to deffuse organic cerebral disease such as arteriosclerosis and head injury.

Good reproduction means that a thing learnt can be recalled and reproduced at any time at a moments notice. It depends on association. Simple fatigue may be responsible for a effect of recall as a cause of amnesia.

Memory may be defined as the power to retain and recall past experiences. Memory defects are common after cerebral lesions and play and important part in causing intellectual defect.

Some people learn a lit very quickly but they also forget a great deal as quickly also. Some people learn quickly and retain for a long time, but they can not reproduce the facts when required. It is a common experience of the candidates appearing in the examination, theory, viva or practical. They very often remember the facts after their examination is just over. Such memory is poor and not serviceable. It must have good reception, retention, reproduction i.e. all the three fundamental qualities. To acquire these one must practice the three laws of memory. Sensory nerves (nerves of knowledge) and Motor nerves (nerves of action) meet at a junction called the synapse. The synapse is a one way valve. Knowledge gained is ance applied and action is the result. It is called a applied whenever needed. Once a nerve impulse travels across a synapse from one nerve to the other, a second impulse will travel the same way again and so on. This means that an action can be easily done in the way it was done before. Trying to change it will be difficult. This fact is very important as it is the basis or learning and habit formation. Law of repetition is based on this. The facts should be arrange in the brain in some order, i.e. in a definite pattern so that they may be firmly fixed or store. They should be arranged in such a logical order that the first one leads to the second, and the second leads to the third as naturally as the door of one room leads to another.

Memory is really stored learning. How this storage is achieved is not yet known to scientists. "Practically nothing is understood about this but it seems much more probable that the storage of memories is a complex function involving extensive area of the brain." Brain.

Latest researches have shown that R.N.A. (Ribo-nucleic acid) plays a key role in memory. So memory has not only anatomical basis but also biochemical, biophysical, physiological and psychological bases.

If anatomy of the brain is disturbed due to injury or disease, there is loss of activity of the area damaged. Great disturbances in speech or its total loss may occur due to injury received in area of the brain concerned with speech. During the last days of Lenin such motor aphasia occurred to him. He understood what was said to him but could not express his thoughts through his mouth. In the same way other motor or sensory areas may be affected and memory concerned with the corresponding area may be impaired or lost. There is localization of brain functions but the several parts cooperate with each other and thus increase the efficiency of each e.g. seeing and touching cooperate with each other to increase the accurate knowledge of objects. Nervous 
system really works as a unity and the efficient working of one centre implies the active cooperation of other centers. The development of the brain consists mainly in the increase of association has been put on the top.

\section{Law Of Neurone Action}

The anatomical basis of learning is well explained by the four laws of Neuron Action formulated by Sandiford. The laws are as follows:

5.1 Law of expression- "Every stimulus of a sensory neuron must have some result, it can not come to nothing." The results may be visible or invisible. William James while talking of habit says, "We are spinning our own fates, good or evil and never to be undone. Every smallest stroke of virtue or of vice leaves its nerve some little scar. The drunken Rip Van Winkle, excuse himself for every fresh direction by saying "I won't count this time." Well he may not count it but it is being counted nonetheless. Down among his nerve cell and fibres the molecules are counting it, registering and storing it up to be used against him when the next temptation comes. Nothing we ever do is, in strict scientific literature wiped out. Every stimulation of the nerves must result in something, it may be obvert of invisible to the eye.

5.2 Law of Least Resistance- " the line of activity chosen by the neural energy to work is the one along which connections between neurons already exist. Habitual use of a nervous tract modifies any inborn connections in such a way that it becomes the preferred path and then it becomes difficult to take any new one, "thus habit becomes second nature. The law is the basis of all habit formation.

5.3 Law of inborn connections- "Due to the inborn connections between sense organs and certain motor nerves the latter will be active whenever particular sensory nerves are excited. Where such inborn connections exist the activity of the nerves automatically takes this line." Thus if we are pricked on the side it is the nearest hand that first comes to the aid and removes the painful stipules. It is only when the hand can not respond that some other organ might work. Reflex activity is governed by this law.

5.4 Law of Acquired Connections- "When any neurone group is stimulated the nerve impulse will be transmitted to the neurone group with which it has been most nearly connected, which has been aroused by it most recently, most frequently, most energetically, for the longest time and with the most satisfaction to the individual." This law is the basis of all learning. All laws of memory may be said to be derived from this one law of Neurone Action.

"Even removal of one hemisphere, if it is not the dominant one, does not abolish memory, and other higher functions of the brain.

The memories are stored in the cerebral cortex has dramatic demonstrations in the observations of Penfield, who found that electrical stimulation of points on the temporal cortex in conscious patients brought forthdistinct mantal pictures of events and the persons involved, or of remembered words, as a song previously memorized. Such memories were complete and specific and resembled dreams, and though they lasted only as long as the stimulus was applied, could be repeated by reapplication of the stimulus. Furthermore there accompanied the evoked memory the emotional pattern attending an original incident remembered. Penfield offers evidence that the integration of memories is not dependent on association system of the cerebral cortex alone but perhaps also on central connections in higher brain stem as was assumed by Hughlings Jackson.

Ranson \& Clark

Plato compared memory to a wax plate which receives impressions of experiences as they occur to us. $\mathrm{He}$ is right to some extent by conceiving memory as something passive. It may be true of early stages of human life. Memory is, as Schopenhaur said, a menial of the will. It is an active agent of life and not a passive wax plate. It implies an active process. It involves a selective activity of the brain. All the impressions that reach the brain are neither attended to nor are they remembered. The brain as a purpose and it selects accordingly. A Students may read a whole book but he remembers what will help him to get through in his examinations.

Nerves of knowledge include not just the nerves of major senses (Sight, Hearing, Smell, Taste, Touch) but also those of minor senses (for heat, cold, pain, pressure, vibration, equilibrium, viscera, heart, hunger, thirst, sex, bones, joints and muscles).

Muscular sense (degree of contraction, resistance overcome, position of part and amount of muscular work done) is very important. Action or work is performed. This in return sends messages to the brain which stores it. It is a common experience that a person writes a word correctly but if asked the spelling before writing he can not say correctly. One can guess the correct weight if the thing is put in the hands. How? Previous association and the storage of the muscular sense in the brain helps.

A person may learn swimming without entering into water and start swimming actually on the first day. A child may start swimming when thrown in water but I have never heard of anyone learning cycling without under going practical training. Practical makes a man perfect. So with every action, several impulses reach the brain through proprioceptive nerves.

A child learns his mother tongue by three practical and natural methods:- 
(i) Hearing (ii) Talking, and (iii) Thinking. An adult has three additional artificial methods (i) Reading (ii) Writing (iii) Teaching. But his progress may be slow if be neglects the natural methods in learning a foreign tongue.

A student must do as much practical work as possible. The gives the brain full opportunities to tap all the sources of knowledge. How does practical work help in memory? This will be clear from the following circuit of messages:-

i. Stimulation (stimulus or message or impulse)

ii. Organ of knowledge (sensory organ)

iii. Nerves of knowledge (sensory nerves or afferent fibres).

iv. Central organ of storage and application (use) of knowledge (Central Nervous System including Autonomic)

v. Nerves of action (motor nerves or efferent fibres).

vi. Organ of action (motor organs, muscles or glands).

vii. Action (visible or invisible).

A person is unaware of the fact that while he is working, a number of messages are continuously relayed to the central nervous system from the organs of action i.e. muscles.

If I am asked what should be done as a first step in order to improve memory, I shall say "Start study" whether you like it or not. The rest will follow.

There are some who can not live or take interest in life without the girl whom they love. But there are some who can always take interest in life whether the girl is of their choice or not. In the same way a person may be an all rounder taking interest in everything, Arts, Science, Commerce etc. He can put his heart and soul into anything which chance has given him. for memory.

Long association with study is bound to create results which in turn will provide the necessary qualities

Statements like, "Teaching improves memory." "Writing makes a man perfect" can be explained on the basis of Memory Laws.

The brain works as a whole and there is a constant interplay between cortical and subcortical functions. Perception evokes emotion and, conversely, emotion provides the interest which activates perception.

"Scoville and Milner (1957) have observed persistent, profound, and generalized loss of recent memory in ten cases of bilateral hippocampal excision. The amnesia being unrelated to any deterioration of the intellect or personality of the subject. Minler (1958) and Walker (1957) both report cases of recent memory impairment after unilateral temporal lobe lesions. It is suggested in explanation either that in such cases the corresponding area on the opposite side must previously have been damaged, or that individual differences perhaps variation in the use of imagery, in some way influence the lateralization of memory function in the brain. However this may be, there is not doubt that bilateral hippocampal lesions are likely to cause permanent and continuing loss of memory for recent events." Brain.

There has been some repletion of certain statements in this article but this effect has been deliberately introduced in order to impress the important points. (Law of Repetition).

If you want to remember anything, read or hear it in the evening before going to bed (i.e. sleep). During sleep brain will have its own reverberating circuits, i.e., associations. At the same time, it will have its rest and will get refreshed. In the morning read or hear the same thing. (Judicious interval of Repetition). You will remember the thing better; in other words you will find improvement in your memory.

\section{Material And Methods}

I did ten experiments in the years 2008 to 2012. The student selected were between 16 and 22 years. Each had at least three failures in his class promotion examination. The students were depressed, disappointed and considered themselves to be of poor memory. They had no hope to pass future examination without failures. Two students were of class VIII, two of High School. Two of Intermediate, two of Medical $3^{\text {rd }}$ year (L.M.P.) and two of Medical $2^{\text {nd }}$ year (M.B.B.S.)

All were guided to follow the three laws of memory, to improve their method of study and to go through one or two books of self improvement series. One more suggestion was given to every one and that may be called unscientific. I include it in Spiritual Science. I shall call it the Spiritual basis of memory. The suggestion was:- "Be religious. Follow your own religion. Have faith in your own Guru or God. If you have no faith, follow your conscience or inner voice or do what you consider right. Don't be guided by temptation. "Don's care for thousand fools. Care for only one learned man." Socrates. If you care for thousand fools, you will be adding one more. So have some righteous method of living according to your own choice. 
This way of living gives purity of mind and a clean conscience. How will this lead to memory improvement, I can't say, but it does improve memory. How does aspirin relive headache may not be explainable but it does relieve headache. So by constant practice the three laws of memory and never overlook its spiritual basis."

\section{OBSERVATION}

All students got success without any failure. The result was cent percent.

\section{CONCLUSION}

It is not right to declare any student a fool or a mediocre. In spite of failures or third divisions, he may have a good memory and intelligence and potential brilliance. The drawbacks might be the wrong method of study, lack of guidance, discouragement, lack of money, time of opportunities, ill health, family troubles, etc.

\section{SUMMARY}

9.1 Memory is the power or capacity of a person to receive, retain and reproduce impressions acquired through nerve of knowledge (sensory nerves).

9.2 It is based on three simple natural laws of remembering: association, impression and repetition.

9.2.1 Brain is an associating machine and considering its size and function, it can put any electronic brain to shame. Thinking (Making Associations) is an indispensable element in recalling.

9.2.2 To get deep and vivid impressions, one must have interest, concentration, accurate and close observation and the use of as many senses as possible including minor senses.

9.2.3 Repetition should be done at judicious intervals.

9.3 The spiritual or moral aspect of personality is always to be kept in mind as an important basis of memory.

9.4 Anyone can improve his or her memory as the laws are based on scientific basis.

9.5 Experiments conducted on 10 students gave cent percent success.

\section{References}

[1] Stoddard, George D. and Carl Emil Seashore, The American Journal of Psychology, Vol.63, No.3, 1950 pp.456-462.

[2] Ranson, S.W. and Clark, S.L., The Anatomy of the Nervous System. $8^{\text {th }}$ Edition, W.B.Saunders, Philadelphia, 1947 . pp.x +532. 